\title{
A LÍNGUA DA CORRESPONDÊNCIA: UMA LÍNGUA PARA A ESCRITA DE SI
}

\author{
LÍVIA LETÍCIA BELMIRO BUSCÁCIO ${ }^{1}$
}

Instituto Nacional de Educação de Surdos

Rua das Laranjeiras, 232, Laranjeiras, Rio de Janeiro, Brasil

liviabuscacio@gmail.com

\begin{abstract}
Resumo. $O$ presente artigo consiste em um gesto de leitura da correspondência de Mário de Andrade enquanto materialidade discursiva, com base na Análise de discurso (PECHEUX, ORLANDI).
\end{abstract}

Palavras-chave: Mário de Andrade; correspondência; Análise de discurso.

\begin{abstract}
This article consists an analysis of correspondence of Mário de Andrade as discursive materiality, based on Discourse Analysis (PECHEUX, ORLANDI).
\end{abstract}

Keywords: Mário de Andrade; correspondence, Discourse Analysis.

Muitos são os estudos dentro da teoria literária que consagram a correspondência como gênero literário. Através de uma leitura da correspondência entre Mário de Andrade, proponho uma análise da correspondência pelas lentes da Análise de discurso (PÊCHEUX, ORLANDI) enquanto materialidade discursiva onde pela prática da escrita de si (FOUCAULT, 2012) é estabelecida uma tensão entre o público e o privado (SOUZA,1997; LEAL, 2011) na qual um sujeito missivista é lançado ao que denominamos por língua da correspondência. Nesta língua, no caso de Mário de Andrade, a troca de cartas por um sujeito que ocupa um lugar de saber, como o dos homens de letras, a correspondência é afetada pela discursividade do arquivo e do autor, em retesamento. E como afirma Candido (2011 [1946]), Mário de Andrade praticava uma "religião da correspondência". Assim, pensando discursivamente, se de um lado, a epistolografia de Mário de Andrade é formada por um gesto de arquivar cartas para fortalecer um imaginário de unidade do autor, já que se trata de uma correspondência entre homens de letras, como prática da vida intelectual; por outro, uma simbiose de dizeres pela fluência do lugar discursivo de correspondente esvai o efeito de propriedade do escrito, no gosto de uma língua para confissão. ${ }^{2}$

O artigo está dividido em três partes: em Escrever-se em cartas: uma prática discursiva, trarei as análises de Foucault (2012 [1992]), Souza (1997) e Leal (2011) sobre a correspondência enquanto prática discursiva; em $O$ "sustentar uma correspondência" em Mário de Andrade, mostrarei dizeres sobre a correspondência de Mário de Andrade de estudiosos de sua epistolografia, como Candido (2011 [1946]), Lopez(1983), Duarte (1971), Demétrio (1998) e Moraes (2001, 2007), analisando-os discursivamente; em

\footnotetext{
${ }^{1}$ Doutora em Estudos da Linguagem pelo Instituto de Letras da UFF. Professora concursada do INES (Instituto Nacional de Educação de Surdos).

${ }^{2}$ Este artigo é oriundo da tese de doutorado Mário de Andrade, um arquivo de saberes sobre a língua do/no Brasil (2014), orientada pela Profa. Dra. Vanise Medeiros e coorientada pelo Prof. Dr. José Luis Jobim.
} 
"Você não sabe que nosso bem é de cartas?: uma língua de confissão", moverei dizeres sobre a escrita epistolar em Mário de Andrade, autor e arquivo, e procurarei formular a noção de língua da correspondência como materialidade discursiva pela Análise de discurso; por fim, em efeito conclusivo, finalizo com Ao sol, carta é farol de um autor que se esvai e fortalece pelo mover discursivo.

\section{ESCREVER-SE EM CARTAS: UMA PRÁTICA DISCURSIVA}

Para se pensar a correspondência discursivamente, é preciso primeiramente retomar Foucault (2012, p. 129-160[1992]), por sua análise das práticas na antiguidade do que denomina a "escrita de si", a partir da leitura das notações da vida cotidiana e das cartas de Atanásio, Plutarco, Sêneca, Epicuro, dentre outros. Conforme nota da edição (idem, p. 129), o artigo "A escrita de si" integra uma série de estudos de Foucault sobre "as artes de si mesmo", que consiste em uma análise sobre as práticas do "governo de si e dos outros" na antiguidade greco-romana, nos dois primeiros séculos do Império, antes do cristianismo, compreendidas como uma "estética da existência" pelo "cuidado de si", publicados nos dois últimos volumes da História da sexualidade: O uso dos prazeres e $O$ cuidado de si.

Segundo Foucault, em sua interpretação de Santo Atanásio, "a escrita de si" mesmo na literatura espiritual cristã se configurava em um modo de ascese, de purificação do pensamento através de uma manutenção da própria conduta pela "presença alheia" (idem, p. 131) na escrita da vida diária, em alternativa ao diálogo oral entre os ascéticos. É, pois, pela escrita, que é possibilitado um momento de suspensão do cotidiano justamente para refletir sobre o cotidiano, logo, sobre si. Desta forma,

a escrita de si mesmo ... atenua os perigos da solidão; dá o que se viu ou pensou a um olhar possível; o fato de se obrigar a escrever desempenha o papel de um companheiro, ao suscitar o respeito humano e a vergonha ....aquilo que os outros são para o asceta numa comunidade, sê-lo-á o caderno de notas para o solitário. (FOUCAULT, 2012, p. 131)

Assim, Foucault afirma que a "escrita de si" se constitui não apenas em um hábito entre os ascéticos, mas também uma maneira de pensamento através de uma práxis que remonta à antiguidade greco-romana. Na leitura de uma "cultura filosófica de si" precedente ao cristianismo, Foucault busca em Epiteto, Sêneca, Plutarco e Marco Aurélio o papel da escrita como uma prática de camaradagem, dos caminhos do pensamento, das atestações de verdade. Citando o terceiro Diálogo de Epiteto, Foucault expõe o exercício da "escrita de si" para um "alívio no pensamento" (EPITETO apud Foucault, 2012, p. 133 [1992]). Por sua vez, Foucault retoma Plutarco, para explicitar que a escrita de si era reconhecida por uma função "etopoiética: um operador da transformação da verdade em ethos" (idem, 2012, p. 134 [1992]), uma forma do homem, enquanto projeção da imagem de si (ethos), ser transformado pela verdade (imaginária) através da escrita. Havia então duas maneiras de escrita etopoiética, os hypomnemata e a correspondência.

Os hypomnemata, basicamente, eram cadernos pessoais de notas sobre a vida cotidiana, que podiam apresentar a forma de um livro de contabilidade ou notarial, mas a prática da escrita de um "livro de vida, guia de conduta" (idem, p. 135) era um hábito entre pessoas consideradas cultas. O caderno de notas desempenha então uma função de acúmulo da vida e da memória pela escrita, sobre o qual seria possível, pela leitura e releitura, meditar, pensar, refletir para alcançar uma tranquilidade. Na prática social da 
escrita dos hypomnemata na antiguidade, não se deveria apenas ler e acumular o dito pelos outros, é necessário um momento de suspensão possibilitado pela escrita de si. Segundo o autor, o objetivo é "retirar-se para o interior de si próprio, alcançar-se a si próprio, viver consigo próprio, bastar-se a si próprio, tirar proveito e desfrutar de si próprio" na prática da escrita de si e da leitura de si (idem, p. 138). Os cadernos de nota funcionam, portanto, pelo exercício de escrita pessoal, como matéria para o envio de escritos destinados ao outro, impulsionando a prática da correspondência.

Afirma Foucault sobre correspondência: "a carta enviada atua, em virtude do próprio gesto da escrita, sobre aquele que a envia, assim como atua, pela leitura e releitura, sobre aquele que a recebe". (FOUCAULT, 2012, p.145). A correspondência, por isso, se aproxima da práxis dos cadernos de notas, mas é uma escrita que de início se dá para um outro.

Além disso, a correspondência apresenta um caráter pedagógico, pela troca de saberes na leitura e na escrita de cartas, no movimento da aceitação e da refutação do que é dito pelo correspondente, configurando um exercício de pensamento pela escrita de si e do outro e pela leitura de si e do outro. Na correspondência, não se trata de uma pedagogia na qual o mestre detém um saber a ser lido pelo discípulo. Foucault cita Sêneca: "Quem ensina, instrui-se" (SÊNECA apud Foucault, 2012, p. 147). Ademais, a escrita de missivas é espaço de aprendizagem para o escritor, "uma maneira de se treinar" (idem, p. 147) tanto na busca pelo conhecimento de si pelo outro como na procura pelo conhecimento da técnica da escrita. Como veremos, este caráter pedagógico comparece na correspondência de Mário de Andrade, conforme os estudos de Moraes (2007).

Para Foucault, a carta atua também como uma espécie de consolação, um meio de lidar com o luto e com a enfermidade, no caminho para uma reflexão sobre o vivido e compreensão da morte como algo inevitável, logo, que deve ser aceito com resiliência. $O$ conselho pela missiva incide não apenas no leitor, mas sobretudo no escritor da carta que, ao orientar o outro, orienta-se, já que a carta "serve de quadro a trocas que a levam a tornar-se mais igualitária" (idem, p. 148). Por isso, é projetado em Mário de Andrade, pelo lugar de escritor de cartas, o "orgulho de jamais aconselhar". Retomando a missiva como uma técnica de escrita, o escritor precisa se fazer 'presente' ao leitor a quem é dirigida a carta, através do comentário da vida, dos infortúnios e do consolo, sobretudo, por na escrita colocar-se face a face com o destinatário, para tamponar as ausências narradas. Também é um modo de apresentar-se pela narrativa do cotidiano, alçando o comum à importância de ser cultivado pela escrita de si para o outro. Com isso, a escrita de cartas é uma prática do descanso e da reflexão sobre a vida, pelo "ocupar-se de si mesmo" (idem, p. 156). É o que está materializado em Andrade, no lugar de correspondente a Tio Pio: "desculpe o lápis. Escrevo como posso no momento, apenas pra não deixar a carta pra depois, desleixada num possível esquecimento ou atropelo de vida." (ANDRADE apud Guaranha; Figueiredo, 2009, p. 189, 3 de agosto de 1931). Por isso, a relação epistolar implica no "colocar a si mesmo sob o olhar do outro" na prática do "exame de si" (FOUCAULT, 2012, p. 157), estabelecendo princípios para uma vida regrada através da correspondência.

Como vimos, a importância do trabalho de Foucault sobre as cartas configura-se na oferta de uma perspectiva discursiva sobre a correspondência, como prática social da "escrita de si". Retomarei alguns desses preceitos, adentrando na Análise de discurso pecheuxtiana. Passemos primeiro às pesquisas de Souza (1997) e Leal (2012) para situar as contribuições no campo teórico e auxiliar no embasamento de nossas formulações, em 
seguida, apresentaremos questões sobre a correspondência, pela leitura do arquivo das cartas de Mário de Andrade.

A pesquisa de Souza (1997) sobre as cartas pessoais enviadas ao Grupo Somos de Afirmação Homossexual elucida importantes aspectos sobre a carta do ponto de vista discursivo. Souza (1997) afirma que a carta pessoal é um espaço discursivo onde o dizer de si, numa esfera privada, é fronteiriço com o público. Nas cartas, Souza analisa "relatos de experiências da gestão de um segredo em um certo setor individual e coletivo da vida" (SOUZA, 1997, p. 49), de modo a estabelecer na carta um lugar para o sujeito "expor a si como sujeito da prática homossexual" (idem). Nessa tensão entre o privado e o público, a correspondência pessoal se configura como uma possibilidade do sujeito estabelecer um "pacto confidencial" (SOUZA, 1997, p. 81), onde se explicita que um sujeito escreve para outro, o remetente toma corpo e se instaura "em relação a um destinatário" (idem, p. $81)$.

A partir do trabalho de Souza (1997), pode-se depreender que, se no dizer de si um outro se encarna, na correspondência esse mecanismo de um sujeito referir-se a seu próprio dizer como se fosse um outro se constitui em um espaço discursivo onde é materializada a heterogeneidade das formações discursivas ${ }^{3}$. Por sua vez, é onde se inscreve uma dispersão do sujeito materializando posições discursivas no cruzamento do lugar do correspondente com outros lugares discursivos. Por se dar na espera do olhar do destinatário, a constituição da carta marca o heterogêneo do discurso, onde se escreve de si para perceber-se pelo outro.

Em sua tese de doutorado, que tem por arquivo as cartas abertas quanto à posse da terra em Roraima, no confronto entre o discurso político e o discurso indígena, Leal (2011) diferencia o funcionamento entre cartas produzidas no privado e no público, sendo as cartas abertas marcadas por um efeito de 'em nome de um nós' para o lugar de remetente, ainda que esse nós silencie e subjugue outros dizeres. Sobre o funcionamento da carta aberta, Leal afirma:

trata-se de cartas divulgadas sempre em nome de uma coletividade, de um grupo. São cartas que, fora das esferas do privado, em vez de serem portadoras de secretas confissões ou confidências e circunscritas ao âmbito pessoal, por exemplo, voltam-se para o público e cujos fins primeiros são solicitação, reivindicação, de divulgação, enfim, uma carta-documento de cunho nitidamente político. (LEAL, 2011, p. 143144)

Para Leal, a carta aberta, destinada a um propósito político, rompe com a confidencialidade da correspondência, funcionando como um documento atravessado pelo imaginário de representação política de uma comunidade, de um grupo. A tensão na carta aberta se dá na esfera do público-público, na qual se inscrevem posições-sujeito em luta pelo discurso político sobre a terra.

Com as contribuições de Foucault (2012), Souza (1997) e Leal (2011) sobre a correspondência, com base nos pressupostos da Análise de discurso e mobilizados pela leitura do arquivo da tese, proponho formular, pela Análise de discurso pecheuxtiana, algumas questões sobre o funcionamento discursivo da correspondência. Em síntese, buscarei trabalhar com quatro noções, que movem uma mesma engrenagem discursiva: a

\footnotetext{
${ }^{3}$ Sobre a heterogeneidade das formações discursivas, ver Pêcheux (2010), Indursky (2007).
} 
correspondência como materialidade significante; o lugar discursivo ${ }^{4}$ de correspondente e a tensão das posições discursivas; a manutenção e a ruptura do confidencial; a relação entre correspondência, sujeito, função-autor e arquivo. É preciso ressaltar que estas noções não serão desenvolvidas de forma estanque, mas despertadas pelo gesto de leitura do arquivo, até por estarmos tratando do funcionamento discursivo por um campo teórico que não concebe o discurso em fatias. Para desenvolver as noções, empreenderei uma leitura do arquivo e de experiências de leitura que me chamam a atenção e podem nos auxiliar na compreensão da discursividade da correspondência.

\section{O "SUSTENTAR UMA CORRESPONDÊNCIA" EM MÁRIO DE ANDRADE}

Começo com um dizer em Mário de Andrade sobre a prática da correspondência entre homens de letras: "Carta de deveras carta, é documento maior. Manu, e matute bem nos que não conseguem escrever carta e muito menos sustentar uma correspondência." (ANDRADE apud Moraes, 2001, p. 386, 7 de abril de 1928). Muitos são os estudos e pesquisas no campo da literatura sobre a correspondência entre intelectuais, artistas, literatos, homens de letras e o papel da epístola como prática da vida literária. Focarei nesta seção a correspondência como prática dos homens de letras em Mário de Andrade. Seguindo um trajeto de dizeres sobre a correspondência de Mário de Andrade, chamarei autores dos estudos literários, de modo a compreender melhor a formação do arquivo e o que circula sobre Mário de Andrade no lugar de correspondente a partir de um outro campo disciplinar. Nesse caminho, também comparecerão dizeres sobre a correspondência materializados em Mário de Andrade. Deve-se considerar que, ao mobilizar saberes e ideias de outros campos, preciso analisá-los e formulá-los por minha inscrição na Análise de discurso.

No caminho do afeto, estabelecer uma correspondência como prática da vida literária é, também, doar-se no elo à amizade pela letra em carta. De Mário para Manu.

Você comenta que a nossa amizade é carteada ... isso não quer dizer nada, Manu! Isso é que é o mais puro mais elevado mais masculino feitio e manifestação de amizade. Você me quer um bem danado no que aliás é certeza que é correspondido ponto por ponto." (ANDRADE apud MORAES, 2001, p. 261, 12 de dezembro de 1925; negrito nosso)

Por outro lado, é preciso "sustentar uma correspondência", gestando "documento maior": na carteação entre Mário de Andrade e Manuel Bandeira, está materializado um imaginário sobre a correspondência que vai muito além do que seria uma troca de cartas. A correspondência ganha possibilidade de formar arquivo, documento, algo que os homens de letras deveriam sustentar como prática da vida literária para se sustentar no lugar social do intelectual. Como efeito desta prática produzido pela função-autor, a correspondência é projetada como arquivo futuro, em um vir a ser registro histórico, objeto de pesquisa posterior. Com isso, a prática da correspondência em Mário de Andrade recai na formação de um "arquivo de si" (ROUDINESCO, 2006), estabelecendo um confronto entre a língua da correspondência e a memória institucionalizada do arquivo, reforçada pelo funcionamento do nome de autor. Uma correspondência entre

\footnotetext{
${ }^{4}$ Sobre lugar discursivo, ver Grigolleto (2008) e Buscácio (2014).
} 
anônimos poderia ser imaginada como "documento maior" no dizer de quem a pratica e a forma do lugar do correspondente?

No aniversário de falecimento de Mário de Andrade, Antonio Candido (1946) escreveu para a Revista do Arquivo Municipal de São Paulo assinalando a grandiosidade do autor e destacou, dentro dos muitos Mários já conhecidos (mas nem sempre tão falados) naquela época, o escritor de cartas.

Com efeito, há muitos Mário de Andrade, além dos conhecidos, que se irão revelando aos poucos. Entre estes o Correspondente, o homem que escrevia cartas. A sua correspondência encherá volumes e será porventura o maior monumento do gênero, em língua portuguesa: terá devotos fervorosos e apenas ela permitirá uma vista completa da sua obra e de seu espírito. (CANDIDO, 1946; grifo nosso)

A prática dessa "religião da correspondência" (idem), na feliz expressão de Antonio Candido, gerou um verdadeiro "monumento" de quase oito mil cartas lacrado a pedido de Mário de Andrade. Na escrita de si por cartas, pode-se ler em Mário de Andrade um efeito de autorização da abertura do arquivo apenas cinquenta anos após a sua morte, em carta-testamento a seu irmão Carlos, publicada por Alvarenga em Mário de Andrade, uт роисо (1972).

Toda correspondência, sem exceção, eu deixo para a Academia Paulista de Letras. Deve ser fechada e lacrada pela família e entregue só para ser aberta e examinada 50 (cinquenta) anos depois da minha morte. (ANDRADE apud ALVARENGA, 1972, p. 32)

Também sobre o caráter monumental da epistolografia de Mário, Telê Ancona Lopez afirma que "Não se consegue ainda avaliar a extensão da correspondência ativa, iniciada talvez antes da década de 20, seguindo até o final da vida de Mário, em fevereiro de 1945" (LOPEZ, 1983). Em carta a Drummond, lê-se em Mário: "Desculpe essa longuidão de carta. Eu sofro de gigantismo epistolar". O gigantismo é o do arquivo de si, no mergulho na discursividade da correspondência.

A correspondência de Mário de Andrade é um monumento, pelo excesso de documentação, mas, sobretudo, pensando pela Análise de discurso, é uma correspondência-monumento fruto de um gigantismo discursivo do autor que também é arquivo $^{5}$, no efeito de reunião do maior arquivo epistolar da língua portuguesa a partir de um nome de autor - Mário de Andrade. Sobre as cartas, é projetada na carta-testamento uma formação futura de um arquivo-monumento, com data para ser aberta essa espécie de caixa de Pandora trancada em um cofre Bernardini pela família. Mário redigia "cartas para serem publicadas. Quando íntimas demais, ele tinha o cuidado de dizer que eram estritamente confidenciais" (DUARTE, 1972, p. 8).

Segundo Moraes (2007), em Mário de Andrade a questão da publicação das cartas é contraditória, o que divide o autor entre "a percepção do valor histórico de seu arquivo epistolar, ao mesmo tempo, por querer resguardar a intimidade de seus correspondentes" (idem, p. 120). Analisamos aqui que esta contradição pode ser lida no dizer de Mário de Andrade sobre a correspondência em diversas materialidades. Conforme citado em Moraes (2007, p. 121), na crônica "Crítica, que gente!” publicada no Diário nacional,

\footnotetext{
${ }^{5}$ Formulei a relação entre função-autor, nome de autor e arquivo na tese.
} 
Mário de Andrade declara sobre o epistolário e a escrita de cartas entre intelectuais e artistas.

Eu possuo um epistolário engraçadíssimo, já bem catalogado e que depois da minha morte, hei de deixar dinheiro para que seja publicado em livro. Não são as cartas de amigos não, é um epistolário só de artistas me agradecendo ou me ofendendo. É o que se pode chamar de cartas graduadas. $\mathrm{O}$ artista por primeiro vem chamando a gente, se não chama de gênio, chama de maior crítico paulista. Fala em orientação modernista (na minha frente todos os artistas ficam modernistas), na proteção minha à arte verdadeira, etc. E acaba repetindo que sou grande. Sucede às vezes que elogio o tal do artista porque acho nele algum valor. Vem carta nova, quase ardente, agradecendo quase de rojo no chão epistolar. Sucede que um dia ataco o mesmo artista por alguma coisa dele que não gostei. Lá vem ódio, gente! Cartas sublimes de comicidade, seu malcriado, seu isto, seu menorzinho, pequetitinho crítico do Brasil!... Mas eu me vingo, não banco São Francisco e outros perdoadores. Pelo meu testamento vai ser tudo publicado em livro. (ANDRADE apud Moraes, 2007, p. 121; grifo nosso)

No gesto do autor organizar um epistolário, separar correspondentes conforme o teor das cartas, consideradas como espaço de debate intelectual e artístico, Mário de Andrade ocupa, ou melhor, é ocupado, por um lugar de arquivista, pela força do "arquivo de si" conduzida pela função-autor. Não são quaisquer cartas a formarem o epistolário, são as cartas que, do lugar de intelectual, de homem de letras, de arquivista em Mário de Andrade, foram designadas por "cartas graduadas". É o efeito de contenção da fluidez da correspondência pela autoria e pelo arquivo que é produzido um epistolário, que é projetada a publicação, que é testamentado sob os efeitos do jurídico, a reclusão das cartas para um arquivo futuro, já sendo arquivo, que, segundo a carta-testamento, deveria ser cuidado por uma instituição pública. Em outra direção, em carta à Murilo Miranda datada de agosto de 1943, na tensão entre o público e o privado, e o privado e o privado, lê-se Mário de Andrade colocando-se veementemente contrário à difusão das correspondências.

Declaro solenemente, em estado de razão perfeita, que quem algum dia publicar as cartas que possuo ou cartas escritas por mim, seja em que intenção for, é filho da puta, infame, canalha e covarde. Não tem noção da própria e alheia dignidade. (ANDRADE apud Moraes, 2007, p. 120)

No dizer de Mário de Andrade sobre as cartas, o paradoxo discursivo é resultado da tensão entre os efeitos da função-autor e do arquivo, no tornar a carta documentomonumento, com a fluidez da correspondência. Ainda que a escrita de si por cartas seja um imperativo da vida literária para o lugar homens de letras, principalmente no vínculo com o nome de autor, na língua da correspondência, o autor é levado a um lugar discursivo cuja propriedade consiste em dissipar a interpelação a uma prática social da autoria, trocando-se no dizer do outro em cartas, descansando da rigidez da autoria. Esta é uma das tensões que alinhavam o arquivo discursivo, como analisei na tese, uma outra, é a disputa por proferir saberes sobre a língua do/no Brasil entre posições-discursivas nos correspondentes. Passemos aos correspondentes aos quais cheguei pelo recorte do 
arquivo $^{6}$ e que compõem a Série correspondências do Arquivo Mário de Andrade administrado pelo IEB.

Bandeira foi quem mais ocupou o lugar de correspondente de Andrade. Conforme Moraes (2001, p. 31), dentro da Série Correspondência do arquivo institucional do IEB, "Manuel Bandeira representa o maior volume de documentos da subsérie correspondência passiva lacrada, perfazendo o total de 281 documentos que cobrem o período que vai de 22 de maio de 1922 a 30 de outubro de 1944". Além disso, Moraes reuniu outros documentos como cartões postais, outras cartas e bilhetes da Série Manuscritos do arquivo Mário de Andrade, incluindo um bilhete sem data com anotações sobre linguistas e a Gramatiquinha; e 14 cartas do Fundo Manuel Bandeira administrado pela Casa de Rui Barbosa, no Rio de Janeiro. Esse monumento-correspondência foi publicado em Correspondência Mário de Andrade \& Manuel Bandeira (2001) pelo projeto editorial Série Correspondência uma parceria do IEB com a EDUSP. Por outro lado, a correspondência com Pio Lourenço foi estabelecida por maior período na epistolografia de Mário de Andrade, compreendida entre 1917 e 1945, tendo sido organizada por Denise Guaranha e Tatiana Figueiredo, publicada pela editora Ouro sobre azul. A publicação da correspondência, do lugar de pesquisador vinculado ao IEB, foi fruto da pesquisa no Arquivo Mário de Andrade e no arquivo privado de Pio Lourenço. Em outra via, as cartas de Mário de Andrade com Sousa da Silveira e outros filólogos e gramáticos, como Antenor Nascentes, Amadeu Amaral, Renato Mendonça, dentre outros, nas quais se materializam dizeres sobre a língua do/no Brasil, ainda se encontram no arquivo do IEB, sem difusão em livro. Novamente, percebe-se a ação do instituto na administração do Arquivo Mário de Andrade, inscrita agora no processo de difusão das correspondências, ou seja, da seleção e do recorte de uma fatia do arquivo para a publicação e distribuição em livros.

Na crítica literária de Mário de Andrade ao conto Dona flor, de Francisco Inácio Peixoto, publicada no Diário de Notícias em 1940, pode-se ler ideias sobre a escrita de cartas no autor. Um professor de música amigo de Mário indicava o violão para alunos menos talentosos no piano e em Mário de Andrade está formulado no lugar de crítico literário sobre a correspondência.

Estou me lembrando disso porque existe uma espécie de violão da literatura, a que poucos dos nossos milhares de escritores se dedicam, o chamado gênero epistolar. É, na verdade, o gênero ideal, de grande nobreza humana porque socializa, aproxima os indivíduos e cultiva a amizade. E ao mesmo tempo, não se publica. Por intermédio das cartas nós podemos dar fuga aos nossos sentimentos e ideias, fazer literatura, mandar contos e crônicas aos nossos amigos, dezenas de sonetos, que serão certamente aplaudidos por eles, de noite e de dia, porque não fazem barulho. É certo que da dezena de volumes já saídos este ano, a maioria não tem exatamente uma razão pública de ser. São legítima literatura de violão. (ANDRADE, 1993, p. 188)

Em Mário de Andrade, a escrita de correspondência era imaginada como um exercício literário, do mesmo modo que o violão era compreendido no processo de aprendizado para o piano. Mas se violão é processo, é principalmente intimidade, um

\footnotetext{
${ }^{6} \mathrm{Na}$ tese, procedi o recorte do arquivo (ORLANDI, 1984) selecionando os correspondentes conforme os seguintes critérios: um nome de autor que ocupe um lugar de saber prestigiado sobre a língua (lugar do gramático, lugar do filólogo, lugar do literato), que tenha ocupado o lugar do correspondente em cartas nas quais emergem discursividades sobre a língua do/no Brasil pelo dizer sobre a escrita literária.
} 
saber privado em partilha, assim como a escrita de cartas. Em Ao sol, carta é farol, Matildes Demétrio afirma sobre a confissão na correspondência de Mário de Andrade: "A correspondência é o apelo irreprimível daquele que escreve e a ressonância de quem recebe" (DEMÉTRIO, 1998, p. 22).

Desse modo, se as cartas resguardam uma prática da vida literária, um hábito público entre escritores, homens de letras, fortalecendo esses lugares em uma formação social, a correspondência também é espaço privado de revelar-se ao outro pela escrita e pela leitura de uma materialidade dada como um presente, um mimo, no íntimo. Entre escritores, a correspondência é atravessamento do dizer sobre a criação literária, da lida pela paixão da língua. Como salienta Moraes (2007, p. 113), a correspondência de Mário de Andrade, ao "fazer da carta o espaço da experimentação" (MORAES, 2007, p. 113) da linguagem, forma o que a crítica genética denomina por "arquivo da criação" (idem, p. 92), ou seja, um meio de se compreender o desenrolar da criação artística.

Para Moraes (2007), nas cartas de Mário de Andrade a questão "estilística" da língua se dá não só no debate filológico com missivistas como Sousa da Silveira e Manuel Bandeira, mas na própria escrita de cartas, ao transgredir "preceitos de uma linguagem privilegiada literariamente mas anacrônica para 'forçar a nota', chamando a atenção para a 'linguagem brasileirista"' (idem, p.113). Conforme Moraes, pelo caminho da escrita de cartas em Mário de Andrade reside uma pedagogia, através da qual o autor

aprofunda temas, instaura a hesitação, incita reações, dialogando com simplicidade. O pedagogo é o doutrinador paciente dos colegas de geração, oferecendo conhecimento técnico e ideológico das tendências modernistas, assimilado de livros e revistas europeias. (MORAES, 2007, p. 113)

Pode-se ler projetado em Mário de Andrade um lugar de guru de uma geração e de mestre, materializado em cartas, ensaios, artigos, livros, vindos da pena de discípulos sobre Mário de Andrade. Lopez (1983) confirma que as missivas de Mário de Andrade constituem um importante documento e objeto de pesquisa, sobretudo, no caso da discussão sobre a língua no Brasil, dita nos estudos literários como "questão da fala brasileira", no lugar de experimento estilístico pelo literato:

É bom destacar a existência de pronunciamentos sobre a questão da fala brasileira, vários, fundamentados na justificativa de sua aplicação à linguagem escrita, apontando fontes e pesquisa, arcando com a responsabilidade da experimentação, principalmente nos anos 20. (LOPEZ, 1983)

Pausa. Este é um dizer do campo dos estudos literários sobre a questão da "linguagem escrita" em Mário de Andrade. Para averiguar os saberes sobre a língua nas cartas de Mário de Andrade, foi imprescindível mergulhar na materialidade da língua pela leitura do arquivo discursivo. Não basta dizer apenas que há uma questão linguística nas cartas, sob o risco de repetir o que foi tornado evidente sobre Mário de Andrade e a língua do/no Brasil por outros campos disciplinares. Como demonstrei na tese, trouxe da

\footnotetext{
${ }^{7}$ Analisei na tese de que modo um dizer sobre o estilo, a estilística de Mário de Andrade produz efeitos no dizer sobre a língua do/no Brasil. A língua brasileira no literato é significada pela posição-gramático e pela posição-literato como abonação literária, inovação, algo aceitável apenas na literatura, excentricidade artística. Mas, ainda assim, passa a comparecer nas gramáticas e manuais escolares brasileiros sobretudo no século XX no lugar do estilo.
} 
correspondência entre Mário de Andrade, Sousa da Silveira, Manuel Bandeira e Pio Lourenço uma teia de dizeres onde residem variadas posições discursivas sobre a língua do/no Brasil na fluência do dizer sobre a escrita literária, marcada justamente pelo trânsito conflituoso entre os lugares autorizados a dizer sobre a língua nestes nomes de autor. Muito além de representarem um espaço de enunciação estritamente relacionado à vida privada, se configuram como um arquivo que difunde saberes sobre a língua e a literatura em relação à formação de imaginários de nacionalidade para o Brasil. Contudo, como o enfoque aqui é tratar mais especificamente da correspondência enquanto materialidade discursiva, não irei analisar sequências discursivas com dizeres sobre a língua.

\section{"VOCÊ NÃO SABE QUE NOSSO BEM É DE CARTAS? UMA LÍNGUA DE CONFISSÃO”}

$\mathrm{Na}$ leitura do arquivo das correspondências, algo ressalta e desperta a curiosidade: o excesso do número de cartas, o tamanho de algumas cartas e o curto intervalo entre uma carta e outra em determinados correspondentes. Muitas das cartas trocadas entre Mário de Andrade e Manuel Bandeira, por exemplo, apresentam a mesma data da carta do remetente ou uma diferença de poucos dias. Na edição de Moraes (2001) da correspondência de Mário de Andrade e Manuel Bandeira, podemos notar que várias cartas apresentam uma mesma data, na marca do nome de autor no lugar do destinatário: "Petrópolis, 16 de março de 1925. Mário" (ANDRADE apud MORAES, 2001, p. 191); “São Paulo, post. 16 de março de 1925. Manuel." (BANDEIRA apud MORAES, 2001, p. 191). As quatro cartas trocadas com Sousa da Silveira têm cerca de dez páginas cada uma, são várias as cartas extensas entre Mário e Manuel, a maioria movendo um dizer sobre a língua de um Brasil em formação pela língua e pela cultura. O que chama um autor para o lugar do correspondente, além de uma prática social entre homens de letras da escrita de si? E o que move um dizer sobre a escrita de si no correspondente, pelo desejo de escrever e receber cartas? O que impele o sujeito no lugar do correspondente os dizeres materializados nas sequências a seguir?

Sua carta me deu um prazer safado! (BANDEIRA apud MORAES, 2001, p. 267; 26 de dezembro de 1925)

tenho tido longas conversas com você. Sabe como? Lendo a correspondência velha. (BANDEIRA apud Moraes, 2001, p. 555; 8 de abril de 1933; grifo nosso)

Manu, outro dia lhe escrevi uma carta sem conversa, pela sua que obrigava resposta pronta. (ANDRADE apud Moraes, 2001, p. 587; 8 de setembro de 1934)

Fui há dias, há muitos dias, surpreendido pelo advento da sua carta de 10 deste, que foi lida com prazer proporcionado à nossa boa camaradagem, multiplicada pelo tempo imenso em que $\mathrm{V}$. se manteve em obstinada ausência dos olhos desta coruja, que preside e fiscaliza a entrada das cartas e dos amigos que me visitam na toca em que passo os dias da velhice. (CORRÊA apud Guaranha; Figueiredo, 2009, p. 319; 24 de outubro de 1938; negrito nosso)

Na solidão desta chácara e deste escritório, onde há 33 anos este cérebro medita na conversação de tantos in-fólios incoerentes e incapazes de auxiliar a companheira a me fazer companhia - aqui passo eu as 
semanas e os meses, esperando e iludindo a espera... Mas esperando o quê? - Nada; esperando... Para não desesperar, para consolar e dourar a espera, esta sua carta tem sido uma das melhores tisanas. Muito Obrigado. (CÔRREA apud Guaranha; Figueiredo, 2009, p. 184; 15 de maio de 1931; negrito nosso)

Desculpe eu lhe ter posto no espírito, na última carta, uma inquietação a meu respeito. Tome apenas por mais uma prova de amizade o meu estouro do último escrito. Há sempre que procurar algum coração amigo, quando se é do meu feitio apaixonado, onde derramar o excesso das inquietações e sofrimentos. Foi o que fiz. (ANDRADE apud Guaranha; Figueiredo, 2009, p. 338; 3 de maio de 1940)

Nas sequências, um dizer sobre o efeito da correspondência no sujeito que ocupa o lugar do correspondente atravessa o nome de autor, indo além de uma prática social da escrita de si. Algo fala no sujeito que o leva a mergulhar no lugar do correspondente, esquecendo de uma unidade de si para buscar-se na escrita do outro sobre si. É o que denomino por língua da correspondência. A correspondência pode ser compreendida como uma materialidade significante, produzindo efeitos no sujeito para além do que possa estar escrito em uma língua escrita oficial (uma língua imaginária, nacional, gramatizada) e mesmo na que fura o oficial pela escrita (uma representação da língua do Brasil na escrita). O sujeito é interpelado a ocupar o lugar de correspondente pela materialidade da correspondência, podendo ser convocado à escrita de cartas pelos efeitos do pacto da confidência, ou pelos efeitos de uma carta-documento, na movência de tensões discursivas entre o privado-privado, o público-privado, o público-público. A escrita de si nas cartas projeta no sujeito uma prática, uma técnica de escrita, que é furada pelo trânsito do efeito dos lugares discursivos de remetente e destinatário para o lugar discursivo de correspondente, nos quais circulam posições-sujeito.

Na língua da correspondência, se por um lado são ditadas normas para o dizer-se em cartas através de uma evidência no sujeito sobre o lugar de correspondente; através da inscrição do outro, de um leitor de cartas que também ocupa o lugar de escrever-se, é estabelecida uma confluência de dizeres pela troca na materialidade significante. Essa materialidade toma forma na expectativa de ler e ser lido na carta, no tempo de aguardo da resposta, no tempo de escrita e da nova leitura, levando o sujeito pelo deslizar na fluência do significante da correspondência.

Cartas em papel, eletrônicas, e-mails, mensagens em sites de relacionamento, privadas e públicas: não seriam distintos suportes, produzindo efeitos em específico, mas constituídos pela materialidade significante da correspondência? O discurso da arte sobre a correspondência também nos auxilia a entender o funcionamento desta materialidade. O trabalho de artistas como Ray Johnson na Mail $\mathrm{Art}^{8}$, por exemplo, se propõe a expor a forma da correspondência no presente, por meio da performance, que se constitui na produção de um modo de escrita de si (a xerox disforme do próprio rosto, por exemplo) para ser enviado, inscrevendo um leitor da correspondência na performance. Pelo discurso artístico sobre a correspondência, diferentes suportes artísticos foram alinhavados, na representação do que seria o tradicional, a carta envelopada, a carta em papel específico para carta; o pombo-correio; e o contemporâneo, o e-mail, o vídeo, as mensagens de texto velozes do celular e das redes sociais, no efeito de um sem forma do digital. Com isso, esse discurso artístico opera no mostrar, através do deslocamento da

${ }^{8}$ http://www.rayjohnson.org/Ray-Johnson-The-Present-of-Mail-Art/. 
carta para a materialidade visual, a possibilidade de diferentes suportes serem escritos na língua da correspondência, exibindo a inscrição do sujeito em duas materialidades: a epistolar e a artístico-visual.

Dois são os efeitos no sujeito ao deslizar pela materialidade significante da correspondência, produzidos pelo esquecimento. Ao ocupar o lugar de correspondente, o sujeito se ilude de controlar a língua da correspondência, reforçando um efeito de unidade de um sujeito cônscio do que envia ao destinatário e do que lê no destinatário; podendo inclusive tentar conter a correspondência no arquivo. $O$ sujeito teria então o poder (imaginário) de juntar cartas, organizar, catalogar, rasgar, descartar, deletar, selecionar os missivistas, no controle da formação de um arquivo das próprias correspondências, em uma prática do "arquivo de si". É esse padecer que se lê em Mário de Andrade. Aliado ao funcionamento do nome de autor, a ilusão de controle do que está escrito, do que foi lido e da possibilidade de um "arquivo de si" ser projetado como um arquivo a ser administrado por uma instituição, salienta ainda mais o efeito de unidade discursiva do autor e do arquivo, pelo domínio epistolar. Contudo, o domínio epistolar, a unidade do autor e do arquivo, bem como o lugar de remetente e de destinatário, são efeitos, ilusões, imaginários no sujeito provocados pelo esquecimento, pela cisão do sujeito atravessado pela ideologia e pelo inconsciente, materializados na língua da correspondência. É pelo deslizamento do sujeito no significante da correspondência que, no lugar de correspondente, as posições discursivas emergem da memória discursiva, roubando a cena de um sujeito centrado, da origem e do controle da escrita de si, soprando o castelo de cartas que faz funcionar no sujeito os efeitos de fortaleza do nome de autor e o arquivo. Desse modo, a língua da correspondência é casa de tensão discursiva.

Não se trata, pela Análise de Discurso, portanto, de verificar a correspondência apenas pela mudança de lugares entre o remetente e o destinatário, procurando averiguar quem disse o quê, tendo em vista que consideramos tratar-se de efeitos de evidência para o lugar de correspondente. Importa muito mais compreender esse processo de funcionamento do lugar discursivo de correspondente, de modo a perceber como um dizer se tensiona no outro através da escrita de si, por meio da imersão de posições discursivas na reatualização da memória.

No caso da análise das correspondências entre Andrade e Sousa da Silveira, Manuel Bandeira e Pio Lourenço, analisei na tese como o trânsito discursivo das posições-sujeito nas cartas se dá na tensão entre o fluir no lugar discursivo de correspondente e os lugares autorizados pelo discurso sobre a língua, verificando como as posições se confluem e se embatem ao veicular saberes sobre a língua no Brasil. Desta maneira, a atuação da carta sobre o sujeito se dá também pela própria resistência do lugar discursivo do correspondente no confronto com outros lugares discursivos: no escrever para um outro, o sujeito se inscreve; no se ler em um outro, o sujeito também se escreve - e os dizeres se confluem e se retesam na "escrita de si". Assim, a movência da língua da correspondência não é pacífica ideologicamente, por se constituir no retesamento próprio do discurso.

O tênue limite entre o público e o privado a que se refere Souza (1997) também se encontra materializado no arquivo da correspondência de Mário de Andrade: ao mesmo tempo em que trocou correspondências privadas com uma enorme lista de destinatários, as missivas de Mário se constituem com "o maior monumento do gênero, em língua portuguesa" (CANDIDO, 1946). No trânsito entre o público e o privado, está materializado, como visto anteriormente, na carta-testamento de Mário, um desejo de 
controle do arquivo da correspondência pelo autor, autorizando a administração do arquivo por uma instituição pública e a publicação das missivas apenas após cinquenta anos de seu falecimento. Além disso, o epistolário de Mário de Andrade - gesto de organização de suas correspondências - onde catalogou as cartas de artistas e críticos acerca de sua obra para posterior publicação, na prática do "arquivo de si". Na tensão desta fronteira, o sujeito abriga posições distintas em relação à correspondência.

A possibilidade de formação do arquivo da correspondência reunido pelo nome de autor, a ser administrado por uma instituição, rompe o pacto de confidencialidade epistolar do privado-privado, para um público-público, que obscurece a tensão privadoprivado no lugar do correspondente. Por outro lado, está materializada no arquivo discursivo a disputa entre o "arquivo de si" e o arquivo resguardado pelo instituto. Mas a língua da correspondência resiste na confidencialidade, no que está materializado entre Pio e Mário, um pacto de uma "franqueza de confessionário" (CORRÊA apud Guaranha; Figueiredo, 2009, p. 111). Vamos brevemente a algumas sequências do arquivo sobre o corresponder-se.

A língua da correspondência em Mário de Andrade se instaura entre o segredo da correspondência e a publicidade de um arquivo do futuro. O segredo do cofre Bernardini que abrigava as correspondências de Mário de Andrade só pode ser aberto em 1995, pois já havia decorrido o prazo estipulado na carta-testamento. Se em Mário de Andrade é possível ler uma posição contrária à publicação das correspondências (MORAES, 2007, p. 120), comparece a projeção e a realização de um arquivo do futuro, com a Série Correspondências do Arquivo Mário de Andrade administrado pelo IEB. Falemos do segredo. O pacto de confidência se desdobra em um inscrever-se no dizer do outro e no resguardar a relação de confidência no lugar de correspondente. Sobre o pacto de confidência em Andrade, lê-se na escrita do poema abaixo, enviado em uma carta a Guilherme de Figueiredo.

\footnotetext{
Guardar as cartas consigo, Nunca mostrar a ninguém, Não as publicar também: De indiferente ou de amigo, Guardar ou rasgar. Ao sol Carta é farol. ${ }^{9}$
}

Como se pode ler no poema que dá corpo à carta, no guardar-se confidencial das cartas, ao ponto de silenciar o próprio dizer na possibilidade de destruí-las, no lugar de correspondente, o sujeito também resguarda um outro, chegando até a cogitar encobri-lo e encobrir-se. Na carta, como um espelho suspenso a girar em torno do próprio eixo no lugar de correspondente, quem é destinado à leitura também se é apropriado da escrita. Por isso, há na carta pessoal uma "relação de similaridade e intercambialidade de posições entre enunciadores" (SOUZA, 1997, p. 81), resultando em um pacto de confidência que sustenta a língua da correspondência, de tal força que é preferível a carta perder-se no abrigo do arquivo de si ou ser apagada pela destruição do que ter transformada a relação privado-privado em público-público. $\mathrm{O}$ trânsito entre os nomes de autor nas cartas estaria salvaguardado pelo pacto de confidência. Nas margens de Amar, verbo intransitivo revisadas por Pio Lourenço, o missivista estabelece um pacto: o dizer sobre a escrita literária, por sua vez, sobre a língua nas correspondências estaria assegurado pela

\footnotetext{
${ }^{9}$ MORAES, 2007, p. 123 apud ANDRADE, M. A Lição do Guru, Carta a Guilherme de Figueiredo, 17 fev. 1945, p. 163.
} 
"franqueza de confessionário" (idem, 2009, p. 111). Mas sobre o arquivo pode pairar um sol, na ruptura pelo funcionamento do arquivo e do autor com o confidencial da correspondência.

Em carta de 10 de outubro de 1924, nota-se em Bandeira, um fluir do lugar de correspondente na língua da correspondência mobilizando um dizer sobre a escrita literária de Andrade em $O$ clã de Jabuti. Na prática da "escrita de si", a carta funciona como aprendizado para o escritor na lida com a poesia na língua, no desenvolvimento técnico do escritor, como vimos em Foucault (2012). Ao mesmo tempo em que a técnica é exercitada no esvanecer a autoria por meio da troca do escrever a quatro mãos, em contrapartida, possibilita o apagar do outro para garantir a manutenção da unidade do autor do poema.

Aqui vão de volta os teus poemas. Li-os, reli-os e, como fiz de outras vezes cortei, emendei, ajuntei, pintei o sete! Tudo, porém, a lápis e levíssimo, de sorte que facilmente se apagam! Fiz como se os versos fossem feitos só para mim e muitas vezes mesmo por mim. Sou teu maior admirador, mas a minha admiração é rabugenta e resmungona. (BANDEIRA apud Moraes, 2001, p. 130; 10 de outubro de 1924)

Pela correspondência, o dizer do literato sobre um outro fazer literatura entra no corpo da escrita poética alheia. Do lugar de leitor, se faz o corte e a emenda na escrita do outro, pela leveza da inscrição a lápis. Os lugares discursivos de escritor e de leitor se atravessam no lugar discursivo de correspondente: se a autoria literária é diluída de modo "levíssimo" pelo missivista, ao mesmo tempo, persiste o efeito de unidade do autor e do remetente, estabelecendo uma tensão entre o autor e o lugar do correspondente. Assim, o lugar de correspondente é ocupado também pelo lugar de escritor, no laço do ler e forjar versos e cartas na escrita do outro, estando a autoria assegurada pela intimidade discursiva da correspondência. No privado-privado, os dizeres se cruzam no confidencial, pois miram de tal maneira a quem se destinam, no efeito de serem ditos só para aquele que lê, que os transformam em seta e em alvo. Pelo pacto de confidência, a marca do outro na escrita literária resguardaria o nome do autor, mantendo a autoria em segredo.

Em contrapartida, a projeção do arquivo em Mário de Andrade impõe à confidencialidade o regime do público-público, pela circulação da correspondência em livros, pela abertura do arquivo administrado pelo Instituto de Estudos Brasileiros: a língua da correspondência é maculada pela língua do arquivo. Ao mesmo tempo, o efeito de unidade do autor corre risco, pois sua escrita é revelada como não sendo somente sua. É essa mácula produzida pela autoria e pelo arquivo na língua da correspondência, que lança o sujeito a professar uma "religião da correspondência" (CANDIDO, 1946).

\section{AO SOL, CARTA É FAROL DE UM AUTOR QUE SE ESVAI E FORTALECE PELO MOVER DISCURSIVO}

Através do funcionamento discursivo da correspondência, verifiquei como a escrita de si se constitui inicialmente como uma prática na qual o sujeito é interpelado a exercer uma demanda da formação social para determinados lugares, e que, na transição do nome próprio para um nome de autor, o sujeito é levado a, do lugar de homem de letras, dizer sobre a escrita de si em uma ilusão do domínio e do controle do dizer aparentemente resguardada pela função-autor. Caminhando nessa demanda, em Mário de Andrade, é projetada uma memória de futuro para o nome de autor, que se materializa no 
dizer sobre o gesto do arquivo de si mirando um arquivo do futuro das cartas. Por outro lado, a língua da correspondência move o nome de autor e esse processo de interpelação para outros rumos, descolando um efeito de unidade do sujeito no nome de autor pela escrita de si, por meio de um pacto de confidencialidade, estabelecido nas tensões entre o público e o privado pelo nome de autor. Através da língua da correspondência, no darse a leitura de um outro pela escrita de si, é possível perceber como em um nome de autor tramas de dizeres se tensionam em um movimento labiríntico. Este labirinto é constituído por uma memória do dizer pelo esquecimento em Mário de Andrade, onde o autor se perde de um suposto domínio e controle do dizer sobre a escrita de si, sobre a propriedade da escrita literária e, por sua vez, sobre a língua. É esse esquecimento resguardado na memória da língua brasileira pelo nome de autor e de arquivo Mário de Andrade, que pode ser lido pela língua da correspondência.

\section{REFERÊNCIAS}

\section{Do arquivo}

ANDRADE, Carlos Drummond de. A Lição do amigo: cartas de Mário de Andrade a Carlos Drummond de Andrade, anotadas pelo destinatário. São Paulo: José Olimpo, 1982. p. 6. Carta datada de 10 de novembro de 1924.

ANDRADE, Mário. Vida literária. Pesquisa, estabelecimento de texto, introdução e notas por Sonia Sachs. São Paulo: Hucitec: Edusp, 1993.

MORAES, Marcos Antonio de (Org.) Correspondências Mário de Andrade \& Manuel Bandeira. $2^{\mathrm{a}}$. ed. São Paulo. EDUSP; IEB, 2001.

GUARANHA, Denise; FIGUEIREDO, Tatiana Longo (Orgs.). Pio \& Mário, diálogo da vida inteira. A correspondência entre o fazendeiro Pio Lourenço Corrêa e Mário de Andrade. 1917 a 1945. São Paulo; Rio de Janeiro: SESCSP; Ouro sobre Azul, 2009.

FERNANDES, Lygia (Org.). Mário de Andrade escreve cartas a Alceu, Meyer e outros. Rio de Janeiro: Editora do autor, 1968.

\section{Teóricas}

ALVARENGA, O. Mário de Andrade, um pouco. São Paulo: José Olympo, 1974.

BUSCACIO, L.L.B. Mário de Andrade, um aquivo de saberes sobre a língua do/no Brasil. Tese. Doutorado em Estudos da Linguagem. Instituto de Letras, UFF, Niterói, 2014.

CANDIDO, A. Mário de Andrade. Revista do Arquivo Municipal, a. 12, n 106, São Paulo, 6973, jan.-fev. 1946. (Reeditada: Revista do Arquivo Municipal, a. 4, nº. 198, São Paulo, DPH, 69-73, $1990 . \quad$ Disponível em http: $/ /$ www.ieb.usp.br/index.asp? categ $=1 \&$ mario $=1 \&$ subcateg $=1 \&$ topico $=43 \&$ inicial $=0$. Acesso em 20 de julho de 2011.)

DEMÉTRIO, M. Ao sol carta é farol: a correspondência de Mário de Andrade e outros Missivistas. São Paulo: Annamblume, 1998.

DUARTE, Paulo. Mário de Andrade por ele mesmo. São Paulo: EDART, 1971

FOUCAULT, Michel. O que é um autor? Lisboa: Ed. Passagens, 2012.

GRIGOLETTO, E. Do lugar discursivo à posição sujeito: os movimentos do sujeito-jornalista no discurso de divulgação cientifica. Em: MITTMANN, S.; GRIGOLETTO, E.; CAZARIN, E. Práticas discursivas e identitarias: sujeito e língua. Porto Alegre: Nova Prova, 2008.

INDURSKY, F. Formação discursiva, essa noção ainda merece que lutemos por ela. Em: INDURSKY, F., FERREIRA, M.C.L. Análise de discurso no Brasil: mapeando conceitos, confrontando limites. São Carlos: Claraluz, 2007. 
LEAL, Maria do Socorro Pereira Leal. Raposa Serra do Sol no discurso político roraimense. Boa vista: Editora UFRR, 2012.

LOPEZ, Telê Porto Ancona. Cartas de Mário de Andrade. O ESTADo DE S. PAULO, Suplemento Cultura, a. 4, $\mathrm{n}^{\mathrm{o}}$ 158, São Paulo, 19 jun. 1983. Disponível em http://www.ieb.usp.br/index.asp?categ $=1 \&$ mario $=1 \&$ subcateg $=1 \&$ topico $=43 \&$ inicial $=0$. Acesso em 18 de julho de 2011.

MORAES, Marcos Antonio de. Orgulho de Jamais aconselhar. A epistolografia de Mário de Andrade. São Paulo: EDUSP; FAPESP, 2007.

. Epistolografia e projeto nacionalista em Mário de Andrade. Gragoatá, Acervos Literários,

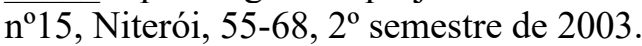

ORLANDI, E.P. Segmentar ou recortar. Linguística: Questões e Controvérsias, publicação do Curso de Letras do Centro de Ciências Humanas e Letras das Faculdades Integradas de Uberaba, Série Estudos, 10, 9-26, 1984.

PECHEUX, M.; GADET, F.; HAK, T. Por uma analise automática do discurso: uma introdução a obra de Michel Pêcheux. $3^{\mathrm{a}}$. ed. Campinas: Editora da Unicamp, 2010.

O discurso: estrutura ou acontecimento. Campinas: Pontes, 2008.

ROUDINESCO, Elisabeth. A análise e o arquivo. Rio de Janeiro: Zahar, 2006.

SOUZA, P. Confidências da carne. Campinas: Ed. da Unicamp, 1997.

Artigo recebido em: março de 2018.

Aprovado e revisado em: agosto de 2018.

Publicado em: dezembro de 2018.

Para citar este texto:

BUSCÁCIO, Lívia Letícia Belmiro. A língua da correspondência: uma língua para a escrita de si. Entremeios [Revista de Estudos do Discurso, ISSN 2179-3514, on-line, www.entremeios.inf.br], Seção Temática [Discurso, arte e literatura - Parte II], Programa de PósGraduação em Ciências da Linguagem (PPGCL), Universidade do Vale do Sapucaí (UNIVÁS), Pouso Alegre (MG), vol. 17, p. 219-234, jul. - dez. 2018.

DOI: http://dx.doi.org/10.20337/ISSN2179-3514revistaENTREMEIOSvol17pagina219a234 